\title{
Solving the location problem of front distribution center for omni-channel retailing
}

\author{
Jikai Huang ${ }^{1} \cdot$ Xianliang Shi $^{1}$
}

Received: 13 September 2020 / Accepted: 16 December 2020

(c) The Author(s) 2021

\begin{abstract}
Consumer demand and retailing models nowadays are being upgraded more frequently. More and more retailers are switching to the Omni-channel retailing model. Choosing a reasonable location for a front distribution center (FDC) helps control an enterprise's cost and improves its service level. This is especially true in the existence of fierce competition. In this paper, two important and contradictory objectives are proposed for the first time in the FDC location problem: minimizing the distribution costs from the facility and minimizing the fixed cost of the facility's location. For these objectives, a bi-objective programming model is established by considering the factors of a facility's capacity, demand and rent fluctuation. Meanwhile, the FDC location problem has been solved by compromising programming and elite set multi-objective simulated annealing algorithm respectively. Taking the FDC locations set of an e-commerce enterprise in a region of Beijing as an empirical sample, this paper uses the above algorithms to re-plan the FDC locations of the enterprise. This algorithm provides support for retail enterprises by helping find the best FDC location. Based on the empirical results, some comments and future research directions are also proposed.
\end{abstract}

Keywords Omni-channel retailing · Front distribution center (FDC) location · Bi-objective programming · Compromise programming $\cdot$ Multi-objective simulated annealing (MOSA) algorithm

\section{Introduction}

As an organic unity of channel, business mode, new technology, and concept, Omni-channel retail has gradually become the direction of transformation for Chinese retailers. According to the report on the development of China's general merchandise retail industry in 2017-2018 (issued by the Ministry of Commerce of China), retailers should take consumer demand, goods, and services as the core of their transformation. Expanding channels, developing new format and optimizing the supply chain has become the future development direction of the Chinese retail industry. In recent years, retailers have been competing for omnichannel retailing at a rapid speed. FreshHEMA, Suning shop, 7Fresh, Yonghui Superstores, and other brands have emerged in omni-channel retail. They provide consumers

Jikai Huang

Hjk03341@163.com

1 School of Economics and Management, Beijing Jiaotong University, Beijing, China with a higher quality shopping experience through variable consumption channels [39, 24], and thus maintain more customer loyalty [35].

Front distribution center (FDC) is a new warehouse allocation mode which integrates retail and distribution in a way that is closer to consumers than traditional storage means. In the omni-channel retailing, FDC brings a great change to the traditional online/offline retailers. The characteristics of 'instant delivery' and 'within reach' of FDC have great advantages in improving the in-store experience and satisfaction of consumption in new the retail era [4,8,52]. Meanwhile, FDC of the major retail giants has expanded rapidly. In only two years, Alibaba Group has 232 FDCs (freshHEMA). Suning, Jingdong, Yonghui etc. retailers are also rapidly developing their own FDCs for omni-channel retailing.

With the rapid development of FDCs, a reasonable location problem of FDCs has become one of the main problems that affect omni-channel retailers' ability to open up new channels and retail formats [41,51]. However, through the review of FDC related papers, it is clear that the research on the FDC location problem of omni-channel retailing is 
deficient. At the same time, the retail industry (such as the XIAOXIANG fresh, freshHEMA, and 7fresh) has had difficulties in operation in several stores due to the facility location problem. This eventually led to strategic store closures.

In this paper, the characteristics of instant distribution and "within reach" are integrated into the FDC location problem of omni-channel retail for the first time. Also, the contradictory problems are selected as the optimization objectives. Based on the p-median model [30], a dual objective location model with an upper limit capacity is established. Combining the compromise programming algorithm and the MOSA algorithm, the upper and lower bound solution sets are provided respectively. Solution sets have a cost tendency. They can provide visualized decision support for decision-makers.

In terms of facility location problem, FDC is different from a traditional warehouse. FDCs are characterized by high distribution density, limited coverage, and are much closer to consumers compared with the traditional warehouses. Additionally, the high distribution density of FDCs (especially in the downtown area) leads to the fixed cost of locations being much higher than traditional warehouses fixed cost. Therefore, this paper uses the bi-objective programming model to solve this problem. Firstly, minimizing the distribution distance ensures a minimum distance cost for consumers' door-to-door shopping. Secondly, minimizing the cost of fixed facilities locations as far as possible helps retail enterprises control costs.

In this paper, a bi-objective programming model, with optimal distribution cost and optimal fixed location cost as objectives, is constructed for the first time to solve the location problem of FDCs.

\section{Literature research}

There are two aspects of literature in this paper. One side is the omni-channel strategy model. Another is the location problem of facilities. This paper briefly reviews the two fields mainly focusing on the research in recent years.

\section{Omni-channel related research}

With the upgrading of the retail market, more attention has been paid to consumers' demand, customer service, and customer experience. Omni-channel retail, as a channel integration strategy, can effectively meet the diversified needs and services of consumers in various consumption scenarios. Therefore, the research on omni-channel retail has attracted more attention in the retail field. Galipoglu et al. Galipoglu et al. [11] analyzed the content of more than 70 articles related to omni-channel retail. The author points out that the research on omni-channel retail mainly focuses on the background of western retail industry, and empirical research is dominant.

In the research on omni-channel retail, omni-channel model is suitable for the "touch" clothing product market. The interactive characteristics and channel integration characteristics of the omni-channel model have a comprehensive and important impact on consumer loyalty [21]. This paper considers that this "touch" is also helpful to the fast-moving consumer goods (FMCG), which can provide consumers with more "reliability". More "reliability" enhances a consumer's intuitive feeling and promotes sales performance by improving trust and loyalty.

The Chinese retail market developed rapidly so the traditional online or offline retail mode cannot meet the needs of consumers to upgrade. Verhoef et al. Verhoef et al. [48] also pointed out the advantage of omni-channel in the research. Omni-channel retail seamlessly integrates the characteristics of physical retail (providing consumers with sufficient consumption experience and feeling) and the characteristics of online retail (giving consumers a wide range of product choices, lower prices, and rich comments). Prabhuram [38] also proposed that omni-channel is an integrated implementation process, which can seamlessly meet the needs and experiences of consumers in multiple channels such as physical stores, customer service centers, mail, online and mobile shopping applications. The omni-channel characteristics, such as collaborative promotion and comprehensive information access between multiple channels, had a significant impact on consumer satisfaction [23]. Therefore, consumption experience, consumption mode, intuitive feeling of a consumer toward a product, and feedback after purchase have a strong impact on consumers. In addition, the shopping experience of omni-channel can affect consumers' purchase intentions [45]. The integration of omni-channel into retail improved the serviceability to the customers, which is the development direction of the future retail industry. Jocevski et al. [20] proposed that the three aspects of a successful transition to an omni-channel retail business management system are: seamless customer experience, integrated analysis system, and effective supply chain and logistics services. This also provides strong support for this paper's view from above.

In the research on the design of omni-channel logistics network, Hübner et al. Hübner et al. [17] pointed out that the planning of omni-channel logistics can be divided into two aspects: the back-end realization (warehouse and instore picking) and the last mile delivery (manned and unattended door-to-door delivery service). The specific design of the link mainly depends on other specific circumstances such as population density and cross-channel process integration ability, customer behavior, etc. The use of spare space for any type of vehicle to replenish inventory for the store is very important. This mode of capacity sharing can 
bring significant economic benefits to enterprises Paul et al. [36]. Abdulkader et al. [1] proposed a two-stage heuristic algorithm and proposed a multi ant colony algorithm for the vehicle routing problem of the omni-channel retail distribution system. Mena et al. [29] mentioned in the study of omni-channel logistics and distribution process that the focus should be on a network sales level, distribution network scale, number of sales personnel, and operation time of network channel. This is to integrate the inventory between stores and distribution channels of omni-channel retailers, so, as to achieve a greater scale effect. Logistics information integration ability and organization integration ability of omni-channel retailers has a significant positive impact on the supply chain integration level. The supply chain integration level has a significant role in promoting enterprise operation performance and financial performance [46]. However, the distribution network under the omnichannel mode contains multiple levels and a wide variety of products. The uncertainty of customer demand should be fully considered [56]. Logistics service quality (especially logistics service timeliness) is an important driving force of consumer satisfaction and loyalty for omni-channel consumers [31]. Retailers need to invest a lot of resources to meet consumers' demand for timely delivery, and the reliability of logistics services. Therefore, effective omni-channel value chain management is the guarantee of a successful operation strategy. Enhancing the quality of multi-channel collaborative service, and digital customer management are the keys to any successful operation strategy $[22,33]$. In terms of the operation strategy of omni-channel supply chain, no matter what the channel structure is, a product exhibition hall can bring benefits to manufacturers, retailers, and the whole omni-channel supply chain [25].

Based on the literature review of omni-channel, this paper concludes that the most important feature of omni-channel is to enrich consumers' shopping choices and experiences, satisfy consumers' diversified consumption demands and improve consumers' purchase intention and satisfaction through the channel integration. However, in the current omni-channel related papers, the research on FDC location cost minimization and delivery time minimization is still relatively scarce.

\section{Location of retail facilities related research}

Facility location is one of the essential factors for the development of many logistics enterprises and physical retail enterprises. It is also one of the strategic issues that must be considered by all channel retailers. In omni-channel retail, the reasonable location of facilities can effectively reduce the time cost of shopping, and improve the consumer experience and loyalty. This will increase the profits of enterprises.
In recent years, research on the location of retail facilities focuses on minimizing cost and maximizing revenue. The problems involved mainly focus on competitive facility location, mode transformation or supply chain network optimization, and providing better services for consumers using big data or consumer behavior research.

In terms of competitive facility location, the reason and starting point of general optimization is to maximize the profit, especially in the two-tier competitive location problem [44]. Marianov et al. [28] studied the impact of characteristics such as one trip and multi-purpose shopping of the same trip on the location of retail facilities in a duopoly market. They proposed that travel for multi-purpose shopping will benefit enterprises significantly. The scale of the shopping center, the diversity of tenants in the shopping center, the retail cluster near the shopping center, the distance to the subway station can affect consumers' preferences [50]. Catering to consumers' preferences and avoiding peer competition is a way to maximize their own profits [37].

In terms of supply chain network optimization, Ahmadi et al. [2] established a mixed-integer linear programming model with the goal of maximizing the total profit of serving customers for the problems of facility location, vehicles, customer allocation, pricing, and path decision-making. They solved it with a branch price algorithm and the Lagrange relaxation method [27] respectively. Millstein and Campbell [1] established an omni-channel warehouse location model for a sporting goods dealer with the goal of maximizing profits and redesigned its retail distribution system. Glaeser et al. [13] consider population, economic data, business location data, and retailer's historical sales and operation data to predict potential locations and demands. using machine learning and econometric methods. The approximate study, Emirhüseyinoğlu and Ekici [7] established a mixed-integer programming model considering the factors of supplier, customer location, customer demand, and supplier price. They studied the dynamic location problem using quantity discount and supplier selection. Glaeser et al. [13] conducted an empirical study on the problem. Based on the conclusions drawn, the authors believe that after improved location configuration and scheduling, enterprises can increase at least $51 \%$ of their revenue. Erdin and Akbas [9] compared the application effects of multi-criteria decision-making (MCDM), TOPSIS and GIS in shopping center location, and used fuzzy sorting method and geographic information system (GIS) to select the location of a shopping center in Turkey. Pagès et al. [34] proposed a facility location model using outsourcing distribution strategy and another using internal distribution strategy to optimize the design of the e-commerce supply chain. They considered the factors of random demand and each customer being served by more than one conventional supplier. 
In terms of providing better services for consumers, Zambrano et al. [54] established a pricing and retail location model considering customer utility and maximum willingness to pay to study the location and pricing of retail stores in a competitive environment. The results show that consumers' willingness to pay will affect the decision of price and facility location. Huang et al. [16] constructed a prediction model for the derived demand of additional products to maximize the expected sales, and help retailers analyze the sales location selection of additional products. Chen et al. [5] studied multiple distinct facilities service location problems (MDFSLP) and designed a fast and iterative local search algorithm (FSILS) to calculate solutions to MDFSLP. Jiang et al. [19] proposed a new method, based on the evaluation of customers' local sensitivity, to solve the competitive location problem by using social media data. They took Beijing data as a sample to find a new retail industry cluster. The authors believe that their research will help people better understand the spatial variation of customer local sensitivity and provide a cost-effective (cost control) competitive location scheme for enterprises.

In terms of competitive location, in recent years, more and more researchers have used integer programming modeling methods and heuristic algorithms. In terms of supply chain network optimization, more researchers use the mixed integer programming method and set the goal to maximize profit. In terms of providing better services for consumers, this study considers more consumer behavior factors, such as consumer utility factor, willingness to pay factor, and consumer evaluation combined with the competitive location problem.

Based on the literature review of the location of retail facilities, this paper believes that the retail facilities under the omni-channel mode should have multiple functions such as physical retail, product display, customer service, and product distribution. For the product positioning of omni-channel mode FDC, its characteristics usually have low added value and complex categories. The distribution of FDC should be as close as possible to the areas where consumers live and/or work, so, as to reduce the distribution cost under the demand of fully guaranteeing the timeliness of distribution. In the related literature research, there is a lack of research considering both distribution cost and facility fixed cost.

\section{Construction of bi-objective location model}

Combing the relevant literature and concepts, the FDC of omni-channel retail is based on the real-time distribution service and distribution in the "surroundings" of consumer living or working locations. Therefore, on the basis of the p-median model, this paper takes the optimization of distribution cost and facility location cost as the objectives. It uses the method of multi-criteria decision-making to model the problem [50].

\section{Problem description and hypothesis}

The distribution cost: FDC is based on real-time distribution service. FDC can not only ensure the timeliness of distribution service but also reduce the pressure of distribution cost for enterprises [40, 57].

The fixed location cost: FDC has the characteristics of large regional distribution density and high location cost compared with the traditional terminal warehouse. While fully ensuring the timeliness and cost of distribution, reducing the cost of facility location can optimize the input for enterprises and improve the input-output ratio.

Therefore, this paper takes two contradictory location problems of distribution cost and fixed cost of facilities as optimization objectives [47], and establishes a double objective optimization model with an upper limit of facility capacity.

The location of FDC in omni-channel retailing has its unique characteristics. It is closer to the customer than a traditional warehouse, and it has multiple retail channels. This paper assumes that the FDC distributed around the consumers is based on the high timeliness of distribution service. The purpose is to realize fast distribution service using the nearest demand point system and provide convenient access to consumers. At the same time, this paper also makes the following assumptions on-site selection:

1. Each demand point is served by at least one FDC.

2. Each FDC has a corresponding facility capacity.

3. FDC operates in the form of venue leases. The author tends to be closer to reality. The paper sets the rental cost to increase by $5 \%$ from the second year by investigating the warehouse currently in operation.

\section{Symbols and decision variables}

Paper suppose that:

$I$ is the set of consumer demand points, $(i \in I=\{1, \ldots$, $n\}, n=|I|)$;

$J$ is the set of potential facilities, $(j \in J=\{1 ; \ldots, m\}$, $m=|J|)$;

$L_{j}$ is the capacity set of potential facilities set $\mathrm{J},(\forall j \in J)$, $(l \in L)$;

Other symbols and the decision variables are defined as follows:

$d_{i j}$ is the distance between consumer $i$ and potential facility $j,(i \in I),(j \in J)$; 
$w_{i}$ is the demand of customer $i,(i \in I)$;

$c_{i j}$ is the single delivery cost from potential facility $j$ to customer $i,(i \in I),(j \in J), x^{2}$;

$p$ is the number of facilities selected;

$l$ is the capacity of potential facility $j,(j \in J),(l \in L)$;

$f_{j l}$ is the fixed cost of potential facility $j$ with capacity $l$, $(j \in J),(l \in L)$;

$q_{j l}$ is the total amount of consumer demand that a potential facility $j$ with capacity $i$ can meet, $(j \in J),(l \in L)$;

$a$ is thefirst year rental cost of potential facility;

$\gamma$ is the annual increase factor of rental cost;

$r$ is the lease term;

$X_{i j}=\left\{\begin{array}{c}1, \text { if customer } i \text { is assigned to facility } j,(j \in J) \\ 0, \text { otherwise }\end{array}\right.$

$Y_{j l}=\left\{\begin{array}{c}1, \text { if potential facility located at } j \text { uses capacity } l,(j \in J) \\ 0, \text { otherwise }\end{array}\right.$

\section{Modeling}

Combined with the above symbolic definitions and assumptions, this section establishes an FDC location model with the objective of minimizing the distribution cost and the facility location cost, respectively.

\section{Minimize distribution costs}

The model of minimizing the distribution cost can be expressed as the formula (1) below. Formula 1 uses the single distribution cost from the selected facility $j$ to the consumer $i$, demand of the consumer $i$, distance from the selected facility $j$ to the consumer $i$, and the part of the selected facility that is established:

Minimize $Z_{d c}=\sum_{i \in I} \sum_{j \in J} c_{i j} w_{i} d_{i j} X_{i j}$

Subject to:

$\sum_{j \in J} X_{i j}=1,(j \in J),(\forall i \in I)$

$\sum_{l \in L_{j}} Y_{j l} \leq 1,(\forall j \in J),\left(l \in L_{j}\right)$

$\sum_{j \in J} \sum_{l \in L} Y_{j l}=p,(j \in J),(l \in L)$

$\sum_{i \in I} X_{i j} \bullet w_{i} \leq \sum_{l \in L_{j}}\left(q_{j l} \bullet Y_{j l}\right),(i \in I),(\forall j \in J),\left(l \in L_{j}\right)$

$\sum_{l \in L_{j}} Y_{j l}-X_{i j} \geq 0,(\forall i \in I),(\forall j \in J),(l \in L)$
$Y_{j l} \in\{0,1\},(\forall j \in J),(l \in L)$

$X_{i j} \in\{0,1\},(\forall i \in I),(\forall j \in J)$

\section{Minimize the fixed cost of location}

The problem of minimizing the fixed cost of facility location can be expressed as the formula (9) below. Using the fixed cost of facilities and the selected retail facilities, formula (9) is:

$\operatorname{Minimize} Z_{f c}=\sum_{j \in J} \sum_{l \in L} f_{j l} Y_{j l}$

Subject to:

Constrains (2) to (8)

$f_{j l}=\frac{a *\left[(1+\gamma)^{r}-1\right]}{\gamma},(\forall j \in J),(l \in L)$

1. Formula (1) is used to minimize the distribution cost of selected facilities

2. Constraints (2) ensures that each customer is served by a selected facility.

3. Constraints (3): each selected facility has only one capacity constraint

4. Constraints (4): the total number of open facilities is $p$.

5. Constraints (5): the capacity of each facility can satisfy the needs of each consumer

6. Constraints (6): the selected facility $j$ with $l$ capacity constraint provides services to consumer

7. Constraints (7) and (8): the decision variables are integer constraints

8. Formula (9): minimization of the fixed cost of selected facilities

9. Constraints (10) denotes the rental cost of the potential facility $j$ satisfying demand $i$.

\section{Solution method}

The facility location problem is a well-known NP-hard problem. In this paper, the weighting method and Pareto optimal set method are used to solve the problem with samples of different sizes under complex conditions. The characteristics of FDC determine a largescale sample of location selections. However, it is inevitable to make small-scale location decisions for the retailer. The weighting method can solve such problems easily. For large-scale or more complex data samples, heuristic and meta-heuristic solutions are usually used. Heuristics and meta-heuristics have better performance 
in scalability, computational performance, and simplicity of application [24].

The location characteristics of FDC in omni-channel mode are different from the traditional single logistics node. To ensure the service quality and timeliness, the service area covered by FDC is usually smaller than the terminal warehouse. This requires higher timeliness and distribution density than the traditional terminal warehouse. Therefore, the location problem of FDC can be regarded as a group location problem, rather than a single logistics node location problem in the traditional sense.

\section{Compromise programming}

There are various methods to solve the problem of multiobjective decision. This paper will draw lessons from the compromise programming (CP) method used by Irawan et al. [17] in the research. This method has been proposed earlier and can solve group decision-making and multi-objective decision-making problems $[53,55)$. Then, Romero and Rehman [42, Romero et al. [43] and Gan [12] have carried on further research on the compromise programming algorithm. They studied the characteristics of the algorithm as far as possible to reach the ideal point. Then, the effectiveness of solving the double objective problem is gradually found. In recent years, Huang et al. [15], Arjomandi et al. 3], and Narayanan et al. [32] have mentioned or used the method of compromise programming in their papers.

In this paper, the ideal solution, anti-ideal solution and compromise solution will be measured by using formula (11) to formula (17). The relationship between the solutions are shown in Chart 1 below.

The parameters of compromise programming are defined as follows:

p istherangeofdistancemeasurement,$[1, \infty]$;

$n$ istheobjectives quantity;

$Z_{i}^{*}$ istheidealsolutionofobjectivei;

$Z_{i *}$ istheanti - ideal solution of objective $i$;

$Z_{i}$ isthe $(x)$ compromise solution (minimizes $L_{p}$ );

$w_{i}$ istheweightofobjectivei;

This paper uses the general formula (11) to measure the position of the ideal solution (Irawan et al. 2017):

$\operatorname{Min} L_{p}=\left(\sum_{i=1}^{n}\left|w_{i} \cdot \frac{Z_{i}(x)-Z_{i}^{*}}{Z_{i *}-Z_{i}^{*}}\right|^{p}\right)^{\frac{1}{p}}$

Setting $p$ to 1 and $\infty$ respectively could maximizes the coverage of the compromise point:
$\operatorname{Min} L_{1}=\operatorname{Min} \sum_{i=1}^{n} w_{i} \cdot \frac{\left|Z_{i}(x)-Z_{i}^{*}\right|}{\left|Z_{i *}-Z_{i}^{*}\right|}$

$\operatorname{Min} L_{\infty}=\operatorname{Min} \Pi$

Subject to:

$\sum_{i=1}^{n} w_{i} \cdot \frac{\left|Z_{i}(x)-Z_{i}^{*}\right|}{\left|Z_{i *}-Z_{i}^{*}\right|} \leq \Pi$

To solve the formula (12), the constraints (3) to (10), and (15) are used:

$$
\begin{aligned}
L_{1}= & \frac{w \cdot\left(\left(\sum_{i \in I} \sum_{j \in J} c_{i j} w_{i} d_{i j} X_{i j}\right)-Z_{d c}^{*}\right)}{Z_{d c *}-Z_{d c}^{*}} \\
& +\frac{(1-w) \cdot\left(\left(\sum_{j \in J} \sum_{l \in L} f_{j l} Y_{j l} X_{i j}\right)-Z_{f c}^{*}\right)}{Z_{f c *}-Z_{f c}^{*}}
\end{aligned}
$$

To solve the formula (13), the constraints (3) to (10), and (16), (17) are used:

$\frac{w \cdot\left(\left(\sum_{i \in I} \sum_{j \in J} c_{i j} w_{i} d_{i j} X_{i j}\right)-Z_{d c}^{*}\right)}{Z_{d c *}-Z_{d c}^{*}} \leq \Pi$

$\frac{(1-w) \cdot\left(\left(\sum_{j \in J} \sum_{l \in L} f_{j l} Y_{j l} X_{i j}\right)-Z_{f c}^{*}\right)}{Z_{f c *}-Z_{f c}^{*}} \leq \Pi$

According to Irawan et al. (2017), there are totally three steps to solve the bi-objective problem with compromise programming. The three steps are: to maximize the objectives, minimize the objectives, and then solve the formula (12) and (13) respectively using constraints (2) to (8) and (10). Solutions of $L_{1}$ and $L_{\infty}$ are the upper and lower bounds of the compromise programming solution set respectively.

\section{Elite set-based multi-objective simulated annealing algorithm}

A simulated annealing algorithm is a stochastic global optimization algorithm. It was proposed by Metropolis in 1953. The original idea is to apply the principle of solid-state annealing algorithm. It heats the solid material to a certain temperature firstly, then the internal elements become active and disordered with the increase of temperature. As the temperature gradually decreases, the elements gradually tend to be orderly and form an equilibrium state at room temperature $[6,10,14,49]$. The 
advantages of the simulated annealing algorithm in convergence speed and jumping out of local optimum are significant.

The multi-objective simulated annealing algorithm based on elite (EMOSA) set is a multi-objective simulated annealing algorithm (MOSA) combined with elite retention strategy in genetic algorithm. The advantage of EMOSA is that it retains a high-quality solution set in the genetic algorithm, and uses the non-dominated sorting operator and density comparison operator [51].

EMOSA retains the high-quality solutions of the parent generation. These high-quality solutions of the parent continue to combine with the offspring to produce more highquality solutions of the offspring. EMOSA can effectively avoid the loss of high-quality solutions of the parent generation in the neighborhood search. The results are presented in a two-dimensional coordinate system in the form of a noninferior solution set, which can directly show the location of each solution set. EMOSA can provide better decision-making assistance for FDC location problems in the region.

According to Zhao and Shen [57], the calculation process of EMOSA is shown below: firstly, the initial solution set is generated randomly. According to the non-dominated sorting method and density comparison operator, the non-dominated level and density of each solution is calculated [10].

Secondly, the MOSA algorithm is used to process the initial solution. Based on the principle of high-quality solution retention, the high-quality parent and offspring are merged for the next iteration until the end of the iteration.

The EMOSA algorithm process is:

1. The initial solution $x_{0}$ is generated firstly, where $X=x_{0}$; $k=0 ; t_{0}=t_{\max } ;\left(t_{0}\right.$ is the initial temperature $)$.

2. To solve $x_{i}$, search $n$ times locally to get the solution $n^{\prime}$ in accordance with the value range of $x$. if $n^{\prime}<0$, the last step will be taken. Otherwise, calculate $\Delta f_{i j 1}=f_{1} x_{j}-f_{1} x_{i}$ and $\Delta f_{i j 2}=f_{2} x_{j}-f_{2} x_{i}$. If both $\Delta f_{i j 1} \leq 0, \Delta f_{i j 2} \leq 0$ are true, or $\exp \left(-\left(\Delta f_{i j 1}+\Delta f_{i j 2}\right) / 2 t k>\right.$ random $(0,1)$, then the highquality solutions $n^{\prime}$ can be accepted. $m$ is the number of accepted high-quality solutions. If $m=0$, then jump to the last step. If $m=1$, then $x_{i}^{\prime}=x_{j}$. If $m>1$, then take the value of the lowest level and the maximum density as $x_{i}^{\prime}$.

3. Finally, $t k+1=\mathrm{d}(t k), k=k+1$. If the conditions meet the requirement, the calculation will be stopped. Otherwise, recalculate the second step [56].

\section{Numerical study}

This paper takes the alternative facilities set of e-commerce enterprises in Haidian district of Beijing as a sample. Haidian district of Beijing has many top high-tech industrial parks and universities. Haidian's degree of economic development in Beijing's regional rankings shows excellent performance. According to the data of the China National Bureau of Statistics, the consumer market in the Haidian district will be very stable and active in 2019. The total retail sales of consumer goods in the Haidian district is 242.16 billion Chinese yuan (second among all districts in Beijing). Among them, the retail sales reached 189.12 billion Chinese yuan, accounting for $78.1 \%$ of the total social retail sales. Therefore, it is representative to select the data set of retail enterprises in Haidian district as the sample.

For the selected empirical enterprises, in order to respect the requirements of enterprises, this paper has hidden the name of enterprises. Therefore, the company is assigned code A. The company A started e-commerce retail business in 2004. After more than ten years of development, it has developed into a large-scale service-oriented enterprise focusing on retail, logistics, technology, science, and technology. Company A is involved in cloud technology, industrial development, retail, digital technology, logistics, technical services, health, insurance, production and development. Due to the factors of Trade Secret Protection Regulations, the desensitization sample set was obtained. This sample set includes the number of alternative facilities (60), number of demand points (200), rent of facilities, the capacity of facilities, demand of customer, longitude and latitude of facilities, and demand points.

According to the section of the solution method, compromising programming and EMOSA are highly suitable for solving such FDC problems. This paper uses the windows 10 platform and Intel Core i5 processor to pre-process the data firstly. Then, the Euclidean distance between the OD pairs is calculated by using GIS software according to the longitude and latitude between the demand points and alternative facilities. Then, this paper uses CPLEX and MATLAB software combined with $\mathrm{CP}$ algorithm and EMOSA to conduct an empirical study.

\section{Solved by compromise programming}

In the solution set of compromise programming, point $\left(Z_{d c}^{\infty}, Z_{f c}^{\infty}\right)$ and $\left(Z_{d c}^{1}, Z_{f c}^{1}\right)$ denotes the upper and lower bound of the solution set of CP respectively. Point $\left(Z_{d c}^{*}, Z_{f c *}\right)$ is the optimal delivery cost, $\left(Z_{d c_{*}}, Z_{f c}^{*},\right)$ is the optimal location fixed cost, $\left(Z_{d c *}, Z_{f c *}\right)$ is the maximum distribution costs and fixed costs. This is shown in chart 2 below.

In this paper, CPLEX software is used to optimize 10, $20,30,40$, and 50 facilities in the sample. The processing information and the calculated results are shown in Table 1 below. 
Based on this sample, the $\mathrm{CP}$ algorithm shows good stability. As for the increase in selection, the performance of the CPU computing time is relatively stable. The specific result of the $\mathrm{CP}$ algorithm is shown in Table 2 below. At the same time, the sample size may lead to unknown limitations of algorithm and calculation. Results show that the solution of the $\mathrm{CP}$ algorithm is more accurate when there are fewer choices. For instance, when the parameter $\mathrm{p}$ is set to 10 , the solutions of $L 1$ and $L \infty$ are similar (which is also a compromise). When increasing the scale of choices, $\mathrm{CP}$ algorithm

Table 1 Compromise programming calculation process

\begin{tabular}{|c|c|c|c|c|c|c|}
\hline \multirow{2}{*}{$\frac{\text { Demand points }(n)}{\text { Facilities points }(p)}$} & & \multicolumn{5}{|l|}{200.00} \\
\hline & & 10.00 & 20.00 & 30.00 & 40.00 & 50.00 \\
\hline \multirow[t]{4}{*}{ Delivery cost (DC) } & Maximize & 742397796.00 & 742397796.00 & 742397796.00 & 742397796.00 & 742397796.00 \\
\hline & CPU time (s) & 2.56 & 2.30 & 2.17 & 2.18 & 2.19 \\
\hline & Minimize & 103528727.00 & 81576932.00 & 74790596.00 & 73084995.00 & 73008068.00 \\
\hline & CPU time (s) & 4.30 & 3.78 & 4.54 & 3.96 & 2.29 \\
\hline \multirow[t]{4}{*}{ Fixed cost of location (FC) } & Maximize & 21759754.00 & 37743740.00 & 52354220.00 & 65847783.00 & 78677233.00 \\
\hline & CPU time (s) & 2.35 & 2.07 & 2.31 & 1.96 & 2.06 \\
\hline & Minimize & 10942767.00 & 23772217.00 & 37265780.00 & 51876260.00 & 67860246.00 \\
\hline & CPU time (s) & 2.55 & 2.54 & 2.37 & 2.56 & 2.42 \\
\hline \multirow[t]{3}{*}{ Compromise Programming (L1) } & Delivery cost (DC) & 11380477.00 & 24345769.00 & 37718584.00 & 51981914.00 & 67860246.00 \\
\hline & Fixed cost of location (FC) & 114346462.00 & 96503411.00 & 88185070.00 & 82621041.00 & 77904658.00 \\
\hline & CPU time (s) & 2.51 & 2.78 & 2.66 & 2.63 & 2.59 \\
\hline \multirow[t]{3}{*}{ Compromise programming $(\mathrm{L} \infty)$} & Delivery Cost (DC) & 11380477.00 & 24451423.00 & 37884612.00 & 52163036.00 & 68011181.00 \\
\hline & Fixed cost of location (FC) & 114346462.00 & 95081779.00 & 86158543.00 & 79452226.00 & 76827561.00 \\
\hline & CPU time (s) & 4.81 & 5.80 & 3.94 & 2.94 & 2.89 \\
\hline
\end{tabular}

Table 2 Solution set of $\mathrm{CP}$

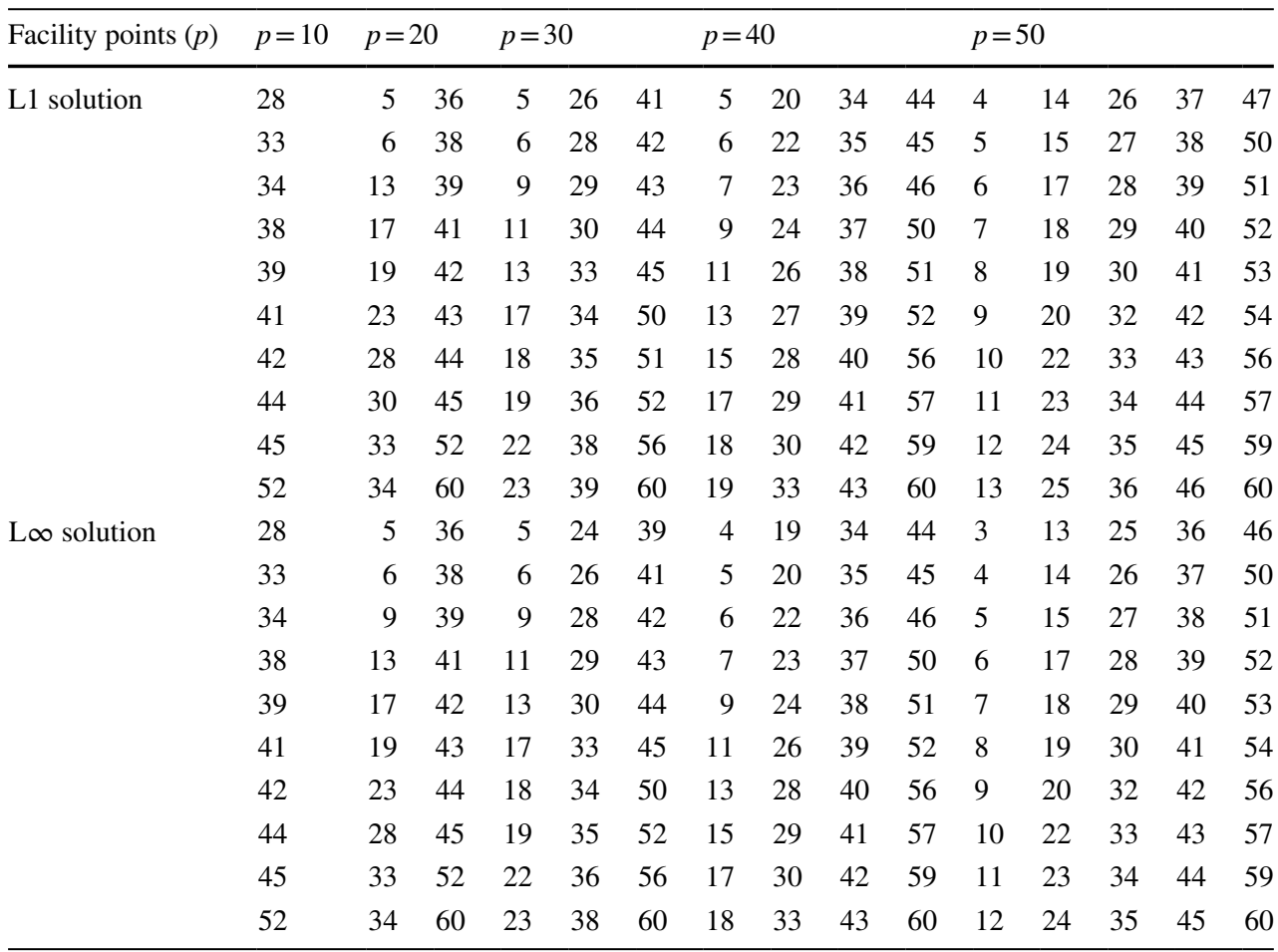


shows another advantage. The advantage is the differentiation of $L 1$ and $L \infty$, meaning different optimization tendency for bi-objectives. For example, when the parameter $p$ is set to 50, $L 1$ and $L \infty$ solutions show more differences than when $\mathrm{p}$ is 10 . The solution $L 1$ is the optimal fixed cost, while the $L \infty$ solution is more inclined to the optimal distribution cost.

When the selected facility points is 10 , the solutions of $L 1$ and $L \infty$ are similar. Retailers can rely on the accuracy of the algorithm. Choosing 28, 33, 34, 38, 39, 41, 42, 44, 45, and 52 points to set up FDCs can shorten the distance between consumers and ensure the optimal fixed cost as expected. However, as the number of choices increased, (for example when it reaches 50 ) the results of $L 1$ and $L \infty$ show a difference of point 3 and 47. However, the optimization direction of CP algorithm is still inclined to the overall optimization (that is compromise). This result can provide retailers with ideal total cost optimization.

\section{Solved by Heuristic algorithm}

The heuristic algorithm appeared in the 1980s, and is also called an intelligent algorithm. It constructs the algorithm logically on the basis of natural laws [1]. EMOSA is used to keep the high-quality solution. It is combined with nondominated sorting and density comparison operator iterating continuously and looking for the global optimal solution randomly. When solving large-scale samples, it will have a more stable and efficient solution results. 11 sets Pareto solutions are calculated by EMOSA shown as below Table 3).

In the EMOSA solution set, each solution has a different characteristic (positioning). EMOSA algorithm is more suitable for solving large samples. Each solution set exists independently and has a distinct personality. Solution set 2 is more inclined to optimal distribution cost. Meanwhile, it is also the choice with the highest fixed cost in the solution set. Solution set 11 tends to optimize the fixed cost of location, but results in higher distribution costs. The solution set 1,4 , $5,7,8$, and 9 are compromise choices. They have a relatively balanced distribution cost and fixed cost. Differentiated solutions can provide decision support for retailers in different market environments. For example, when the demand in a region is small, the retailer can choose an option of the location with the lower fixed cost. When there is a strong demand in a region, shortening the distance between FDC and consumers may be a better choice. Retailers can also make a balanced choice such as the solution sets 1, 4, 5, 7, 8, and 9. However, it also depends on whether the FDC's revenue can continue to be profitable. In other words, whether or not the demand is stable and sufficient. This scheme has a good effect on large-scale samples. It can help enterprises make appropriate decisions and promote their profits and development.

\section{Results and discussion}

The FDC location problem of omni-channel mode is studied using p-median model. The characteristics of FDC are large distribution density, limited coverage, close to consumers' work or home location (instant delivery), facilities with a certain capacity limit, and rent floating. In this paper, a biobjective programming model is established to minimize the distribution cost and fixed cost of location. The reasonable

Table 3 Solution of EMOSA

\begin{tabular}{lrrrrrrrrrr}
\hline $\begin{array}{l}\text { Pareto solu- } \\
\text { tion set }\end{array}$ & \multicolumn{1}{l}{ Selected location points } \\
\hline 1 & 42 & 7 & 23 & 28 & 36 & 41 & 57 & 33 & 5 & 37 \\
2 & 42 & 7 & 23 & 28 & 36 & 41 & 57 & 5 & 37 & 24 \\
3 & 43 & 42 & 7 & 23 & 28 & 36 & 41 & 57 & 54 & 5 \\
4 & 43 & 6 & 44 & 41 & 28 & 26 & 35 & 18 & 60 & 46 \\
5 & 6 & 35 & 34 & 37 & 45 & 15 & 29 & 38 & 13 & 39 \\
6 & 5 & 26 & 43 & 60 & 6 & 35 & 34 & 37 & 45 & 33 \\
7 & 9 & 44 & 23 & 41 & 42 & 12 & 15 & 45 & 39 & 19 \\
8 & 38 & 6 & 9 & 44 & 23 & 41 & 42 & 12 & 15 & 45 \\
9 & 38 & 6 & 9 & 44 & 23 & 5 & 41 & 42 & 43 & 29 \\
10 & 50 & 38 & 6 & 9 & 44 & 23 & 5 & 41 & 60 & 42 \\
11 & 38 & 6 & 9 & 44 & 23 & 5 & 41 & 60 & 42 & 43 \\
\hline
\end{tabular}




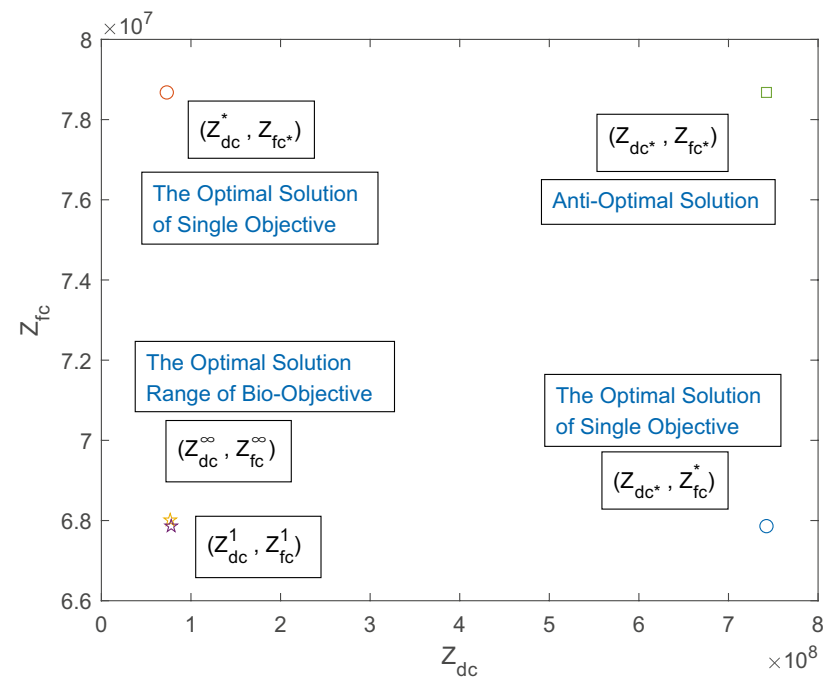

Fig.1 Compromise programming solution

location and planning of FDC can help retail enterprises to reduce operating costs, improve service efficiency, gain consumer trust and loyalty, and then promote the increase of enterprise revenue.

This paper expounds on the FDC layout of omni-channel retailers. It also makes an empirical study on the problem through compromise programming and elite based multi-objective simulated annealing algorithm. Compromise Programming has a high accuracy and computing speed when calculating data samples below a certain scale. The solution $L 1$ and $L \infty$ represent the optimization contents of the two objective functions respectively. The output of the results is presented in Fig. 1, which gives decision-makers a more intuitive feel of the optimization results of the two objective functions. The result of compromise programming is in the form of a solution set. It is highly applicable to FDC, which is a problem with high location density.

EMOSA is a metaheuristic algorithm, which has advantages in solving large-scale samples. The speed of the algorithm is mainly related to the sample size. Obviously, a large range of samples needs more time to solve. It is like most other metaheuristics. In addition, the accuracy of the algorithm is worthy of affirmation. Given enough iterations, the accuracy of the solution set can be guaranteed effectively. This is related to the characteristics of the algorithm. In the end, the EMOSA solution set is highly readable. Each solution is presented in the form of a diagram (Fig. 2). The optimization tendency of the solution to the two objectives can be judged intuitively. It is an intuitive help for decisionmakers to make decisions.

In future research, the authors are going to look at combining the content related to market competition, product management, and consumer behavior.
Fig. 2 Scatter diagram of ENOSA solution set

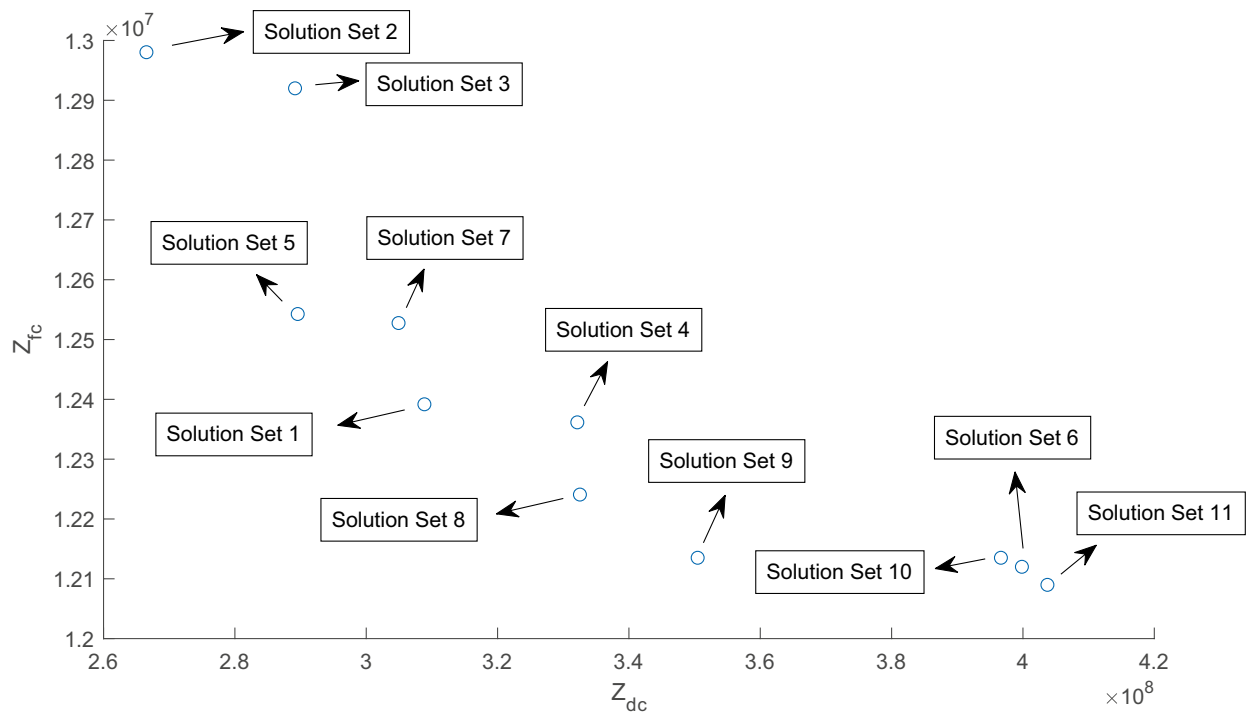


Acknowledgements This paper is financially supported by Fundamental Research Funds for the Central Universities (No. 2019JBZ111).

\section{Compliance with ethical standards}

Conflict of interest On behalf of all authors, the corresponding author states that there is no conflict of interest.

Open Access This article is licensed under a Creative Commons Attribution 4.0 International License, which permits use, sharing, adaptation, distribution and reproduction in any medium or format, as long as you give appropriate credit to the original author(s) and the source, provide a link to the Creative Commons licence, and indicate if changes were made. The images or other third party material in this article are included in the article's Creative Commons licence, unless indicated otherwise in a credit line to the material. If material is not included in the article's Creative Commons licence and your intended use is not permitted by statutory regulation or exceeds the permitted use, you will need to obtain permission directly from the copyright holder. To view a copy of this licence, visit http://creativecommons.org/licenses/by/4.0/.

\section{References}

1. Abdulkader MMS, Gajpal Y, Elmekkawy TY (2018) Vehicle routing problem in omni-channel retailing distribution systems. Int J Prod Econ: S0925527317303584.

2. Ahmadi JA, Amiri E, Meskar M (2018) A profit-maximization location-routing-pricing problem: a branch-and-price algorithm. Eur J Oper Res 271(3):866-881

3. Arjomandi A, Mortazavi SA, Khalilian S, Garizi AZ (2020) Optimal land-use allocation using MCDM and SWAT for the Hablehroud watershed. Iran Land Use Policy 100:104930

4. Budak G, Chen X (2020) Evaluation of the size of time windows for the travelling salesman problem in delivery operations. Complex Intell Syst:1-15.

5. Chen YS, Chu HH, Sangaiah AK (2019) Identifying ambient service location problems and its application using a humanized computing model. J Ambient Intell Hum Comput 10(6):2345-2359

6. Diaz CR, Delgado SDR, C D. et al. (2019) Joint programming of production-maintenance tasks: a simulated annealing-based method. Int J Simulat Model (IJSIMM) 18(4).

7. Emirhüseyinoğlu G, Ekici A (2019) Dynamic facility location with supplier selection under quantity discount. Comput Ind Eng 134:64-74

8. Erdil A (2018) An overview of sustainability of transportation systems: a quality oriented approach. Tehnicki vjesnik Tech Gazette 25(2):343-353. https://doi.org/10.17559/TV-20170618125022

9. Erdin C, Akbaş HE (2019) A comparative analysis of fuzzy topsis and geographic information systems (GIS) for the location selection of shopping malls: a case study from Turkey. Sustainability 11(14):3837

10. Fu HC, Liu P (2019) A multi-objective optimization model based on non-dominated sorting genetic algorithm. Int J Simulat Model 18(3):510-520

11. Galipoglu E, Kotzab H, Teller C et al (2018) Omni-channel retailing research-state of the art and intellectual foundation. Int J Phys Distrib Log Manag 48(4):365-390

12. Gan J, Colletti JP, Kolison J (1996) A compromise programming approach to integrated natural resource management. In: proceedings of the 1994 symposium on systems analysis in forest resources: management systems for a global economy with global resource concerns, Oregon State University, 378-386.
13. Glaeser CK, Fisher M, Su X (2019) Optimal retail location: empirical methodology and application to practice: finalist-2017 M\&SOM Practice-Based Research Competition. Manuf Serv Oper Manag 21(1):86-102

14. Gocken T, Yaktubay M (2019) Comparison of different clustering algorithms via genetic algorithm for VRPTW. Int J Simulat Model 18(4):574-585

15. Huang M, Wang L, Li W, Fan S (2020) Research on traffic control optimization method for oversaturated intersection group. CICTP 2020:722-727

16. Huang T, Bergman D, Gopal R (2019) Predictive and prescriptive analytics for location selection of add-on retail products. Prod Oper Manag 28(7):1858-1877

17. Hübner AH, Kuhn H, Wollenburg J et al (2016) Last mile fulfilment and distribution in omni-channel grocery retailing: a strategic planning framework. Int J Retail Distrib Manag 44(3):228-247

18. Irawan CA , Imran A , Luis M (2020) Solving the bi-objective capacitated p-median problem with multilevel capacities using compromise programming and VNS[J]. Int Trans Opera Res

19. Jiang W, Wang Y, Dou M et al (2019) Solving competitive location problems with social media data based on customers' local sensitivities. ISPRS Int J Geo Inform 8(5):202

20. Jocevski M, Arvidsson N, Miragliotta G et al (2019) Transitions towards omni-channel retailing strategies: a business model perspective. Int J Retail Distrib Manag 47(2):78-93

21. Kinnunen $\mathbf{N}(2015)$ The role of channel integration and interactivity in the customer loyalty creation in an omnichannel fashion retail environment: case bik bok. rapid communications in mass spectrometry 29(14): 1297-306.

22. Kurunathan D, Shanmugathas S, Ashoka K (2019) Analysis of relation between customer behavior and information technology market. J Syst Manag Sci 9(1):87-104

23. Lee W (2020) Unravelling consumer responses to omni-channel approach. J Theor Appl Electron Comm Res 15(3):37-49

24. Li J, Pan SX, Huang L, Zhu X (2019) A machine learning based method for customer behavior prediction. Tehnicki vjesnikTechnical Gazette 26(6):1670-1676. https://doi.org/10.17559/ TV-20190603165825

25. Li K, Liu J, Wan L et al (2015) A cost-optimal parallel algorithm for the 0-1 knapsack problem and its performance on multicore CPU and GPU implementations. Parallel Comput 43(3):27-42

26. Liu L, Feng L, Xu B et al (2020) Operation strategies for an omnichannel supply chain: who is better off taking on the online channel and offline service? Electron Commer Res Appl 39:100918

27. Li ZY, Hai JT (2019) A capacitated location-inventory model with demand selection. J Adv Transp 2019:2143042

28. Marianov V, Eiselt HA, Lüer-Villagra A (2018) Effects of multipurpose shopping trips on retail store location in a duopoly. Eur $\mathrm{J}$ Oper Res 269(2):782-792

29. Mena C, Bourlakis M, Ishfaq R et al (2016) Realignment of the physical distribution process in omni-channel fulfillment. Int $\mathrm{J}$ Phys Distrib Logist Manag

30. Min JN, Jin C, Lu LJ (2019) Split-delivery vehicle routing problems based on a multi-restart improved sweep approach. Int J Simul Model (IJSIMM) 18(4).

31. Murfield M, Boone CA, Rutner P, Thomas R (2017) Investigating logistics service quality in omni-channel retailing. Int J Phys Distrib Log Manag 47(4):263-296

32. Narayanan R, Liu A, Rangaswamy M (2020) An information elasticity framework for the adaptive matched filter. IEEE Trans Aerosp Electron Syst

33. Nazifa TH, Ramachandran KK (2019) Information sharing in supply chain management: a case study between the cooperative partners in manufacturing industry. J Syst Manag Sci 9(1):19-47 
34. Pagès BA, Ramalhinho H, Juan AA et al (2019) Designing e-commerce supply chains: a stochastic facility-location approach. Int Trans Oper Res 26(2):507-528

35. Patalas-Maliszewska J, Klos S (2019) The effect of knowledge sharing using customer relationship management systems in manufacturing companies. Tehnicki vjesnik Tech Gazette 26(1):1-6. https://doi.org/10.17559/TV-20150323135944

36. Paul J, Agatz N, Savelsbergh M (2019) Optimizing omni-channel fulfillment with store transfers. Transp Res Part B Methodol 129:381-396

37. Pelegrín B, Fernández P, Diego PJ et al (2019) Threshold distance versus side payment to reduce the cannibalization effect in retail chain expansion. IMA J Manag Math 30(1):105-123

38. Prabhuram T, Rajmohan M, Tan YC et al (2020) Performance evaluation of omnichannel distribution network configurations using multi criteria decision making techniques. Ann Oper Res 288(1):435-456

39. Quang HN, Huu TD (2019) Factors preventing the way to success of the retail supply chain. J Syst Manag Sci 9(2):114-122

40. Qiu Y, Zhao XN, Zhang XH (2019) Optimal routing for safe construction and demolition waste transportation: a CVaR criterion and big data analytics approach. Tehnicki Vjesnik Tech Gazette 26(4):1128-1135

41. Rasi RE, Hatami D (2019) Environmental risk and innovation in supply chain: analysis of influence of supply chain agility. J Syst Manag Sci 9(3):1-25

42. Romero C, Rehman T (1989) Multiple criteria analysis for agricultural decisions. Elsevier Science, Amsterdam

43. Romero C, Tamiz M, Jones DF (1998) Goal programming, compromise programming and reference point method formulations: linkages and utility interpretation. J Oper Res Soc 49(9):986-991

44. Shan W, Yan Q, Chen C et al (2019) Optimization of competitive facility location for chain stores. Ann Oper Res 273(1-2):187-205

45. Shi S, Wang Y, Chen X et al (2020) Conceptualization of omnichannel customer experience and its impact on shopping intention: a mixed-method approach. Int J Inf Manage 50:325-336

46. Song SH, Shi XL, Song G (2019) Supply chain integration in omni-channel retailing: a human resource management perspective. Int J Phys Distrib Log Manag 50(1):101-121
47. Ünal AN, Kayakutlu G (2020) Multi-objective particle swarm optimization with random immigrants. Complex Intell Syst: 1-16.

48. Verhoef PC, Kannan PK, Inman JJ (2015) From multi-channel retailing to omni-channel retailing: introduction to the special issue on multi-channel retailing. J Retail 91(2):174-181.

49. Wang B, Xie H, Xia X et al (2019) A NSGA-II Algorithm hybridizing local simulated-annealing operators for a bi-criteria robust job-shop scheduling problem under scenarios. IEEE Trans Fuzzy Syst 27(5):1075-1084

50. Wu SS, Kuang H, Lo SM (2019) Modeling shopping center location choice: shopper preference-based competitive location Model. J Urban Plan Dev 145(1):04018047

51. Xuan W, To NC (2018) New retail versus traditional retail in e-commerce: channel establishment, price competition, and consumer recognition. Ann Oper Res.

52. Yi S, Liu X (2020) Machine learning based customer sentiment analysis for recommending shoppers, shops based on customers' review. Complex Intell Syst: 1-14.

53. Yu PL (1973) A class of solutions for group decision problems. Manage Sci 19(8):936-946

54. Zambrano-Rey G, López-Ospina H, Pérez J (2019) Retail store location and pricing within a competitive environment using constrained multinomial logit. Appl Math Model 75:521-534

55. Zeleny M (1974) A concept of compromise solutions and the method of the displaced ideal. Comput Oper Res 1(3-4):479-496

56. Zhang S, Zhu H, Li X, et al. (2019) Omni-channel product distribution network design by using the improved particle swarm optimization algorithm. In: Discrete Dynamics in Nature and Society, 2019

57. Zhao N, Shen YD (2008) Multi objective simulated annealing algorithm based on elite strategy. J Wuhan Textile Univ 021(003):13-17

58. Zhao PX, Luo WH, Han X (2019) Time-dependent and bi-objective vehicle routing problem with time windows. Adv Prod Eng Manag 14(2): 201-212, https://doi.org/10.14743/apem2019.2.322

Publisher's Note Springer Nature remains neutral with regard to jurisdictional claims in published maps and institutional affiliations. 